\title{
SECONDARY REFLECTION AS
}

\section{INTERPRETATION*}

In a note of January 7,1914 , in the beginning of his Metaphysical Journal, Gabriel Marcel writes that "the problems by which I am preoccupied at present are for the most part problems of method."1 At the time he was intent on "avoiding both realism and pure subjectivism," in working out a space for religious faith. Many years later, in reflecting back upon his efforts, Marcel offered this assessment:

\begin{abstract}
In rereading these already dated texts, I have the feeling that I was nonetheless still dominated at that time by the spirit of abstraction I have never ceased fighting since then, and indeed even then I was tempted to recognize the limits of idealism. All the same, it was as an idealist that I was speaking. ${ }^{2}$
\end{abstract}

One of his idealist assumptions regarded his lack of appreciation for "the immediate." "From the standpoint of immediate existence nothing can be explained or even understood. "(MJ, 1) Empiricism, as a philosophy of the immediate, is self-destructive. "The immediate is the very reverse of the principle of intelligibility." (MJ, 1) Knowledge is not given in realistic fashion, through a process of the mind receiving content from immediate experience because "Thought cannot really have an internal content unless it gives it to itself, that is to say, unless it mediates that which is given to it as external...." (MJ, 113) Reflection brings general conditions of intelligibility to bear on the immediate, constituting the immediate into "objectivity," rendering a coupling between existence and objectivity to account for

\section{•For Robert Lechner}

1 Metaphysical Journal. tr., Bernard Wall (Chicago: Regnery, 1952). Hereafter MJ.

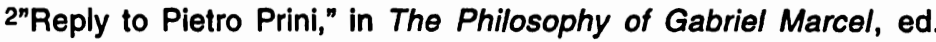
Schilpp and Hahn (LaSalle, III.: Open Court, 1984), p.240. 
intelligibility. The proper mode of an intelligible object is "spatial" or ideal. The notion of truth follows upon intelligibility: "to speak of truth regarding what is outside of existence is a contradiction in terms." (MJ, 29) With this understanding of intelligibility in place, Marcel attempts to make room for faith by posing several aporias. How can the mind arise to an awareness of its functioning (its limits) if its knowledge is solely defined by its categories? How can non-temporal and necessary philosophical claims about the functioning of the mind be reconciled with the categorical functioning of the mind, which is temporally bound? Any solution to these difficulties, according to Marcel, pushes one beyond the level of existential, categorical, intelligibility.

Marcel, to his credit, kept pushing and questioning his own analyses until the reader soon senses a dramatic change of tone in the Metaphysical Journal. In an entry of May 1, 1920, he acknowledges his "evolution in the direction of realism," and also that he "cannot see exactly where it is heading." (MJ, 238) What pushed him in his "realistic" direction was his probing of "participant experience" over against the sense of the "general conditions of intelligibility," which formerly defined intelligibility. Marcel noted that body as it is lived affectively, my body, is not at all intelligible in terms of the general conditions of objectivity. The level of existence is one of immediate participation wherein the subject/object categories subtending idealism are out of place. Objectification by reflection would not render, as Marcel previously held, existence to be intelligible, but would rather distort something that by its nature is resistent to objective analysis. He finally admitted in a note of February 2,1922 that he has reached the point where he must "effect a radical dissociation between the ideas of existence and objectivity." (MJ, 281)

Being and Having, 3 the continuation of his journal entries from 1928-33 and his essay "On the Ontological Mystery" (1933), 4 carried on Marcel's struggle with problems of method, culminating in his notions of problem/metaproblem, primary/ secondary reflection,

${ }^{3}$ Being and Having, tr. Katherine Farrer. (New York: Harper and Row, 1965). Hereafter BH.

4Gabriel Marcel, "On the Ontological Mystery," in The Philosophy of Existentialism, tr.. Manya Harari (New York: Citadel, 1961). Hereafter OM. 
blindfold intuition. The intelligibility of a metaproblem involves one's personal participation, whereas the intelligibility of a problem is extrinsic to the investigator. Primary reflection is the impersonal analysis correlative to problems, while secondary reflection, "the high instrument" of philosophy, is correlative to the metaproblematic. The challenge of secondary reflection is to think participation without transforming it into objective deformation. It is crucial to note that Marcel adamantly rejects the identification of the metaproblematic with the unknowable: "We must carefully avoid all confusion between the metaproblematic and the unknowable. ...The recognition of the metaproblematic...is an essentially positive act of the mind." $(\mathrm{BH}, 118)$ The great difficulty which besets Marcel's philosophy lies in explicating the "essentially positive" element in his definition of secondary reflection. One could say that his whole philosophy depends on validating this element.

Pursuing his "realistic" tendencies in Being and Having, Marcel writes that "the possibility of the realist definition of truth is implied in the nature of thought. Thought turns toward the Other, it is the pursuit of the Other." $(\mathrm{BH}, 30)$ Yet it is clear that the original contact with this Other takes place on the level of an immediate participation which itself cannot be defined as a knowledge. It is here that Marcel introduces his notion of "intuition': "It seems to me that I am bound to admit that I am- anyway on one level of myself - face to face with Being. In a sense I see it. In another sense I cannot say that I see it since I cannot grasp myself in the act of seeing it. The intuition is not, and cannot be, directly reflected in consciousness." (BH, 98) Secondary reflection is defined as "a thinking which stretches out towards the recovery of an intuition which otherwise loses itself in proportion as it is exercised. ...(Secondary reflection) is a recovery, but only in so far as it remains the tributary of what I have called a blindfold intuition." (BH,118; 121)

Marcel's realistic tendency, his grounding of knowledge in Being ["...knowledge is contingent on a participation in Being for which no epistemology can account because it continually presupposes it." $(O M, 18)]$ has moved a commentator such as Francisco Peccorini to identify Marcel's realism with that of Aristotle's.Peccorini claims that "the nature of the famous blind intuition is ...presented as being no more than the self- 
consciousness of the soul insofar as the latter is aware of her power to know and become everything that is knowable."5 Marcel's realism is depicted by Peccorini as one of "common sense immediate realism." The difficulty with this reading is that it neglects the fact that Marcel himself refers constantly to secondary reflection as "recollection" and that he places himself in the Platonic tradition. 6 Marcel's realism of the blindfold intuition grounds reflection in experience, which, to reiterate, is not itself knowledge: "All thought transcends the immediate. The pure immediate excludes thought.... But this transcendence implies a magnitude and even a teleology." (BH, 38; emphasis added) Reflection feeds off of (is a "tributary" of) participant experience, which guides it. The "recovery" of the immediate is never itself depicted as immediate realism by Marcel. In fact he goes to great pains to convince us of the indirect character of an affirmation or articulation of experience.

Let us admit that Being has first laid a sort of siege to the self; by self I mean the subject who affirms. This subject none the less intervenes between being and the affirmation, in the role of a mediator. And then the problem arises which I observed in my notes of January the 19th, for I am inevitably led to ask which is the ontological standing of this self in relation to the being which besieges him. Is he whelmed in it, or does he on the contrary have some sort of command over it? (BH, pp. 14041; emphasis added)

Thus Marcel's realism, regarding any knowledge of experience, is not direct or naive: "The intuition is not, and cannot be,directly reflected in consciousness." (BH, 98) The subject is the nexus between the insertion in being and the assertion of being. This very break between being and its affirmation is the place where Paul

5Francisco Peccorini, “Marcel's 'Blind Intuition' as Man's 'Ontological Foundations'," in Contributions of Gabriel Marcel to Philosophy, ed. William Cooney (Lewiston, New York: Edwin Mellen Press, 1989), p. 87.

6Cf. "On the Ontological Mystery," for numerous identifications of secondary reflection and recollection. Cf. the "avant propos" of the French edition of The Mystery of Being, Vol. I where Marcel identifies the life of reflection as une veritable anamnèse, and claims for his work the label néosocratisme. 
Ricoeur, one of Marcel's finest and most appreciative commentators, raises his major criticism of Marcel. Perhaps a passage from "On the Ontological Mystery" will point out the source of Ricoeur's uneasiness. Marcel writes that the metaproblematical "takes place within an affirmation which I am rather than an affirmation which I utter, by uttering it I break it, I divide it, I am on the point of betraying it." (OM, 18) This is not an untypical passage, one which warns of the distortive potential of articulation. Ricoeur is concerned that Marcel's critique of primary reflection - instrumental reason, technique, calculation - has led him to reject reason entirely: "Without denying that this is indeed the present condition of reason, I do not see how one can understand the ontological affirmation without at the same time undertaking a deliverance of reason from its scientico-technological abasement."7 In other words, Marcel seems to Ricoeur to use secondary reflection as a via negativa: the body is not a tool, sensation is not communication, the Other is not an object, etc., without rehabilitating reason in a way to positively explicate and argue about experience. To Ricoeur, Marcel's criticism of reason has pushed him in a mystical direction, despite his best intentions. One might say that Ricoeur's own philosophy has taken up this challenge of rehabiliting secondary reflection.

Ricoeur is right to the extent that Marcel more often than not employs secondary reflection as critique. However, there are times when Marcel uses secondary reflection positively, constructively, and in ways that prefigure Ricoeur's own project. One of these ways can be found in Marcel's views about the relationship between art, philosophy and life, particularly his use of drama to fictionally portray life. But perhaps the way that is closest to Ricoeur's own work is Marcel's treatment of narrative.

In the chapter "My Life," of the first volume of The Mystery of Being 8 Marcel takes up the question of self-knowedge. He rejects the idea of "an objectively valid answer" to the question "Who am I?".

7Paul Ricoeur, "Gabriel Marcel and Phenomenology," in The Philosophy of Gabriel Marcel, p. 490.

8 The Mystery of Being, Vol. I, tr. G.S. Fraser (Chicago: Regnery, 1960). Hereafter MB 1. 
While reflection affords a certain "detachment" in regard to life, it fails to produce a "pure subject" who has an unsituated knowledge. He draws an analogy between recollecting life and making artistic judgements:

\begin{abstract}
...everything seems to indicate that it would be risky to the last degree to seek, in the judgements of men at some given time, for the definitive and irrevocable: for our appreciations of a work of art are always, say what we will to the contrary, affected by the 'climate of the age,' they reflect the unconscious general assumptions which we share with our contemporaries during some given period in history; the historically conditioned attitude is something which, for all of us, is quite inescapable; and perhaps we cannot even imagine, without tangling ourselves in contradictions, a dehistoricized attitude in the name of which completely objective judgments, judgments quite untainted by the local, the temporal, the personal, and in a word quite free from relativity, could be made about works of art, literature, and philosophy. (MB I, 196-97)
\end{abstract}

The positive feature of recollection which Marcel introduces is the notion of understanding one's life as a narrative.

My life presents itself to reflection as something whose essential nature is that it can be related as a story....and this is so very true that one may be permitted to wonder whether the words 'my life' retain any precise meaning at all, if we abstract from the meaning we attach to them any reference whatsoever to the act of narration. (MB I, 190)

The relation of narrative to life is not realistic for "it is impossible...for me to tell the story of my life just as I have lived it." (MB I, 191) One does not "mirror oneself" through narrative. Narrative presents life "as a sequence of episodes along the line of time" (MB I, 191), but the sequence is "selective" and is a "summary," and not a documentary "reproduction." "Imagination" enters into the constructive dimensionof narration, a putting into shape of life in terms of meaningful episodes. The constructivist dimension ("a fresh construction of an old site") recognizes that "my life, as it has really been lived, falls outside my thinking's present grasp." (MB I, 191) Narrative, however, is not sheer construction imposed willy-nilly upon 
the pure immediacy of life, because narrative, for Marcel, makes "allusion to something which, of its very nature, will not let itself be fully expressed in words, and which is something I have lived through." (MB I, 193) Narrative, can awaken "an echo, set certain strings vibrating" (MB I, 193) by a "luminous flash." The reference to "light" in his later works is meant to cover what he used to call the blinded intuition: "We cannot, I think, ...capture (being itself) or seize it, any more than we can see the source giving off light. I think that this comparison between being and light is a fundamental one." 9 While the immediate "will not let itself be fully expressed in words" (emphasis added), a certain degree of adequacy is possible.

Marcel comes to see the positive dimension of secondary reflection most clearly in art. Here thinking and understanding are clearly interpretive. Just as a writer's work is not its "grossly material nature" (MB I, 195), but a source to draw life from "by opening ourselves to it and interpreting it for ourselves," so one's life does not consist of material effects of an objective nature. That is why narrative is necessary. Narrative is an instance wherein language, utterance, expression are not of themselves distortive of experience. While not reproducing experience, they can "image" it. In turn the expressions of experience call to one another for recognition and confirmation, offering an alternative mode of universality and verification: "...in art sujectivity tends to pass over into an intersubjectivity which is entirely different from the objectivity science honors so much, but which nonetheless completely surpasses the limits of the individual consciousness taken in isolation." (TWB, 6)

Marcel's use of narrative as a construction "nourished" by participant experience is an example of a positive use of secondary reflection. In this instance, reflection is clearly "interpretation." The emphasis upon thusly "elaborated" experiences and their dialogical intelligiblilty and verification proffers the notion of a universality which is indeed a rehabilitation of reason as against the third person processes of objective thought. Not only does this interpretive turn in Marcel's thought lead to a more positive notion of secondary reflection and the fraternal character of philosophy, but it leads him

9Tragic Wisdom and Beyond, tr. Jolin and McCormick (Evanston, III.: Northwestern University Press, 1973), p. 14. Hereafter TWB. 
also to unequivocally side with a democratic politics. 10 While these notions are not highly developed in his work, nonetheless, in both of these ways Marcel can be seen to prefigure the work of Ricoeur.

\section{Villanova University}

THOMAS W. BUSCH

10Cf. "The Responsibility of the Philosopher in Today's World", in TWB. 